Research Article

\title{
Depression during COVID- I 9 Pandemic in India: Findings from an Online Survey
}

\author{
Jugal Kishore', Tanu Anand ${ }^{2}$, Heena ${ }^{3}$, Tamanna Nazli4 \\ ${ }^{1}$ Director Professor \& Head, Department of Community Medicine, VMMC \& Safdarjung Hospital, New Delhi, India. \\ ${ }^{2}$ Scientist D, Indian Council of Medical Research, New Delhi, India. \\ ${ }^{3}$ Statistician, Department of Community Medicine, VMMC \& Safdarjung Hospital, New Delhi, India. \\ ${ }^{4}$ Research Officer, Central Council for Research in Unani Medicine, MoAYUSH. \\ DOI: https://doi.org/10.24321/2454.325X.202008
}

\section{I $\quad \mathbf{N} \quad \mathbf{F} \quad \mathbf{O}$}

\section{Corresponding Author:}

Dr. Tanu Anand, Indian Council of Medical Research, New Delhi, India.

E-mail Id:

drtanu.anand@gmail.com

Orcid Id:

http://orcid.org/0000-0003-2911-2332

How to cite this article:

Kishore J, Anand T, Heena, Nazli T. Depression during COVID-19 Pandemic in India: Findings from an Online Survey. Int J Preven Curat Comm Med 2020; 6(2): 16-21.

Date of Submission: 2020-10-26

Date of Acceptance: 2020-11-25

\section{$\begin{array}{llllllll}\mathbf{A} & \mathbf{B} & \mathbf{S} & \mathbf{T} & \mathbf{R} & \mathbf{A} & \mathbf{C} & \mathbf{T}\end{array}$}

Introduction: Unprecedented crisis of COVID-19 pandemic has generated uncertainties in minds of people thereby impacting their mental health. Global evidence supports rising trend of symptoms of depression among general population during the pandemic.

Material and Method: It was a cross-sectional study conducted between April 15 and May 01, 2020. Data were collected using pre-structured questionnaire that was circulated through a web-based link via messages and mails. Depressive symptoms were assessed using Patient Health Questionnaire-9 (PHQ-9). Data were analyzed using SPSS version 23.

Result: Out of the total 500 telephonic contacts who were sent the survey link, 478 had (95.6\%) responded. There were 114 (23.8\%), $64(13.4 \%), 40(8.4 \%)$ and $29(6.1 \%)$ participants who were classified as having mild, moderate, moderately severe and severe depression respectively. Female gender, religion, education status, unemployment and professional occupation, income less than Rs. 20000 and more than Rs. 40000, 'scare for coronavirus infection' were found to be significantly associated with severity of depression $(p<0.05)$. Adjusted analysis revealed that age was protective factor where as those who were scared from coronavirus infection were found to be two times more at risk of having symptoms of depression. Increasing family income was also associated with presence of depressive symptoms.

Conclusions: The proportion of participants with depressive symptoms was $51.7 \%$. There is a need for assessing psychosocial impact of COVID-19 among populations and communities in varied settings over a long period of time.

Keywords: SARS-CoV-2, Psychosocial Impact, PHQ-9

\section{Introduction}

The entire world is currently battling with Coronavirus Disease (COVID-19) caused by Severe Acute Respiratory
Syndrome Coronavirus -2 (SARS-CoV-2). Unprecedented crisis of COVID-19 pandemic has generated uncertainties in minds of people thereby impacting their mental health. 
It is well known that public health emergencies tend to affect the health, safety and well being of individuals and communities. And these effects translate into long lasting psychosocial consequences among the affected populations. ${ }^{1}$ Though life-threatening viral infection may not result in trauma, a criteria required for diagnosis of Post-Traumatic Stress Disorder, but depressive and anxiety disorders, still may supervene. ${ }^{1,2}$

Global evidence supports rising trend of symptoms of depression, anxiety and stress related to COVID-19 among general population resulting from stressors such as life disruption due to nationwide lockdowns, fears of illness and economic loss, stress of social isolation and worry about health of self and loved ones..$^{3-8}$ Human beings are social creatures and being isolated from the love, support and contact of family and friends for long period of time, can trigger depression or aggravate the existing symptoms.

COVID-19 pandemic has resulted in population undertaking restricted mobility and social contacts. Little is known about status of mental health of general population during COVID-19 pandemic. Therefore, the present study was undertaken to assess the presence of depressive symptoms among general population in Delhi.

\section{Material and Methods}

Study settings and study participants: It was a cross-sectional study conducted between April 15 and May 01, 2020. Data were collected through a pre-structured questionnaire, which was circulated through a web-based link via messages and mails. The study participants included all individuals aged 15 years and above and were telephonic contacts of the investigators.

Exclusion Criteria: All the telephonic contacts who were less than $<15$ years or the telephone numbers which were invalid were excluded from the study.

Sample Size and Sampling: Taking $14 \%$ as the proportion of people in India with some or other mental health morbidity, ${ }^{9}$ sample size was calculated as 186 with precision of $95 \%$ and $5 \%$ alpha error. However, the survey link was shared with 500 telephonic contacts of the investigators.

Study Tool: A self-administered questionnaire was designed that contained items to collect demographic details of the participants, their mental status during COVID-19 pandemic in India and Patient Health Questionnaire-9 (PHQ-9). ${ }^{10}$ PHQ-9 is an instrument which aids in making criteria based diagnoses of depressive and other mental disorders commonly encountered in primary care. It scores each of the nine DSM IV criteria for depression as " 0 " (not at all) to " 3 " (nearly every day) and thus, overall score ranges from 0 to 27 . The total score is interpreted as follows:

\begin{tabular}{|c|c|}
\hline Total Score & Interpretation \\
\hline $1-4$ & Minimal depression \\
\hline $5-9$ & Mild depression \\
\hline $10-14$ & Moderate depression \\
\hline $15-19$ & Moderately severe depression \\
\hline $20-27$ & Severe depression \\
\hline
\end{tabular}

Study Methods: The data were collected using online platform. Participant information sheet and consent form were also included in the survey link. The contacted participants would only participate in the survey if they gave consent to participate. The survey lasted for 5 minutes only (average 4-6 minutes). All the responses were marked mandatory for submission of the form. This ensured completeness of data.

Statistical Analysis: The data were entered in Microsoft Excel 2007 and analyzed using SPSS version 23. Descriptive statistics were used to characterize the study population. Association between categorical variables was assessed using Chi Square test (or Fischer exact test). P-value $<0.05$ was considered as significant. The factors which were found to be associated with severity of depression with p-value $<0.20$ were entered into step forward logistic regression analysis. Adjusted odds ratio were calculated and independent predictors of presence of depression were found.

Ethical considerations: The study was approved by Institutional Ethics Committee of the research institution. Privacy and confidentiality of study participants were assured. The informed consent were obtained from the participants through online mode. For telephonic contacts between 15-18 years written assent was also obtained in addition to informed consent from their respective parents.

\section{Result}

Out of the total 500 telephonic contacts who were sent the survey link, 478 (95.6\%) had responded. There were $54.8 \%(n=262)$ males and 66.7\% $(n=319)$ Hindus. More than half of the respondents aged $\leq 30$ years $(n=252$; $52.3 \%)$. A large proportion of participants were either having professional or postgraduate degree ( $n=259 ; 54.2 \%)$. There were 267 individuals (55.9\%) who were professionals while 152 (31.8\%) were unemployed. There were 18.3\% $(n=81)$ participants whose monthly income was less than Rs. 20000. More than half of the participants belonged to upper socio-economic status ( $n=248 ; 51.9 \%$ ) according to Modified Kuppuswamy Scale. There were 114 (23.8\%), 64 (13.4\%), 40 (8.4\%) and 29 (6.1\%) participants who were classified as having mild, moderate, moderately severe and severe depression respectively (Table 1). 
Table I.Socio-demographic profile and severity of depression among study participants

\begin{tabular}{|c|c|}
\hline Variables & Total $\mathrm{N}=478(\%)$ \\
\hline \multicolumn{2}{|l|}{ Gender } \\
\hline Female & $216(45.2)$ \\
\hline Male & $262(54.8)$ \\
\hline \multicolumn{2}{|l|}{ Religion } \\
\hline Hindu & $319(66.7)$ \\
\hline Muslim & $123(25.7)$ \\
\hline Christian & $12(2.5)$ \\
\hline Sikh & $11(2.3)$ \\
\hline Others & $13(2.7)$ \\
\hline \multicolumn{2}{|l|}{ Age (in years) } \\
\hline$\leq 30$ & $252(52.3)$ \\
\hline 31-45 & $131(27.6)$ \\
\hline $46-60$ & $84(17.8)$ \\
\hline$>60$ & $11(2.3)$ \\
\hline \multicolumn{2}{|l|}{ Education } \\
\hline Illiterate, Literate up to high school certificate & $47(9.8)$ \\
\hline Higher secondary certificate & $33(6.9)$ \\
\hline Graduate degree & $139(29.1)$ \\
\hline Professional degree/ Post-graduate & $259(54.2)$ \\
\hline \multicolumn{2}{|l|}{ Occupation } \\
\hline Unemployed & $152(31.8)$ \\
\hline Unskilled worker & $7(1.5)$ \\
\hline Skilled worker & $52(10.9)$ \\
\hline Professional & $267(55.9)$ \\
\hline \multicolumn{2}{|l|}{ Income $(n=442)$} \\
\hline$\leq 20000$ & $81(18.3)$ \\
\hline 20001-40000 & $74(16.7)$ \\
\hline $40001-60000$ & $80(18.1)$ \\
\hline$>60000$ & $207(46.8)$ \\
\hline \multicolumn{2}{|l|}{ Socio-economic status } \\
\hline Lower & $9(1.8)$ \\
\hline Upper Lower & $44(9.2)$ \\
\hline Lower Middle & $40(8.4)$ \\
\hline Upper Middle & $137(28.7)$ \\
\hline Upper & $248(51.9)$ \\
\hline \multicolumn{2}{|l|}{ Severity of Depression } \\
\hline Mild Depression & $114(23.8)$ \\
\hline Moderate Depression & $64(13.4)$ \\
\hline Moderately severe Depression & $40(8.4)$ \\
\hline Severe Depression & $29(6.1)$ \\
\hline None & $231(48.3)$ \\
\hline
\end{tabular}


Table 2.Association of severity of symptoms of depression with socio-demographic profile of study participants and perception of fear about corona

\begin{tabular}{|c|c|c|c|c|c|c|}
\hline \multirow{2}{*}{ Variables } & \multicolumn{4}{|c|}{ Depression Severity } & \multirow{2}{*}{$\begin{array}{l}\text { Chi } \\
\text { square }\end{array}$} & \multirow{2}{*}{ P-value } \\
\hline & None & Mild & Moderate & Severe & & \\
\hline \multicolumn{7}{|l|}{ Gender $(\mathrm{N}=478)$} \\
\hline Female $(n=216)$ & $94(43.5)$ & $47(21.8)$ & $42(19.4)$ & $33(15.3)$ & 13.59 & $0.004 *$ \\
\hline Male $(n=262)$ & $137(52.3)$ & $67(25.6)$ & $22(8.4)$ & $36(13.7)$ & & \\
\hline \multicolumn{7}{|l|}{ Religion ( $N=478$ ) } \\
\hline Hindu $(n=319)$ & $167(52.4)$ & $79(24.8)$ & $36(11.3)$ & $37(11.6)$ & 12.07 & $0.007^{*}$ \\
\hline Muslim (n=123) & $47(38.2)$ & $28(22.8)$ & $25(20.3)$ & $23(18.7)$ & 11.63 & $0.009 *$ \\
\hline Christian ( $n=12$ ) & $3(25.0)$ & $6(50.0)$ & $1(8.3)$ & $2(16.7)$ & 5.19 & 0.158 \\
\hline Sikh $(n=11)$ & $7(63.6)$ & $0(0)$ & $1(9.1)$ & $3(27.3)$ & 4.67 & 0.197 \\
\hline Others $(n=13)$ & $7(53.8)$ & $1(7.7)$ & $1(7.7)$ & $4(30.8)$ & 4.34 & 0.227 \\
\hline \multicolumn{7}{|l|}{ Age (in years) ( $N=478$ ) } \\
\hline$\leq 30(n=252)$ & $113(44.8)$ & $67(26.6)$ & $34(13.5)$ & 38 (15.1) & 3.17 & 0.366 \\
\hline $31-45(n=131)$ & $64(48.9)$ & $30(22.9)$ & $19(14.5)$ & $18(13.7)$ & 0.31 & 0.959 \\
\hline $46-60(n=84)$ & $50(59.5)$ & $13(15.5)$ & $11(13.1)$ & 10 (11.9) & 6.10 & 0.107 \\
\hline$>60(n=11)$ & $4(36.4)$ & $4(36.4)$ & $0(0)$ & $3(27.3)$ & 3.87 & 0.276 \\
\hline \multicolumn{7}{|l|}{ Education $(\mathrm{N}=478)$} \\
\hline $\begin{array}{l}\text { Illiterate, Literate up to high school } \\
\text { certificate }(n=47)\end{array}$ & $17(36.2)$ & $5(10.6)$ & $7(14.9)$ & $18(38.3)$ & 26.06 & $0.000 *$ \\
\hline Higher secondary certificate $(n=33)$ & $14(42.4)$ & $7(21.2)$ & $6(18.2)$ & $6(18.2)$ & 1.31 & 0.726 \\
\hline Graduate degree $(n=139)$ & $61(43.9)$ & $40(28.8)$ & $25(18.0)$ & $13(9.4)$ & 9.40 & $0.024^{*}$ \\
\hline $\begin{array}{l}\text { Professional degree/ Post-graduate } \\
\qquad(\mathrm{n}=259)\end{array}$ & $139(53.7)$ & $62(23.9)$ & $26(10.0)$ & $32(12.4)$ & 9.77 & $0.021 *$ \\
\hline \multicolumn{7}{|l|}{ Occupation $(\mathrm{N}=478)$} \\
\hline Unemployed $(n=152)$ & $53(34.9)$ & $37(24.3)$ & $27(17.8)$ & $35(23.0)$ & 22.96 & $<0.001^{*}$ \\
\hline Unskilled worker $(n=7)$ & $4(57.1)$ & $0(0)$ & $0(0.0)$ & $3(42.9)$ & 6.74 & 0.081 \\
\hline Skilled worker $(n=52)$ & $20(38.5)$ & $13(25.0)$ & $11(21.2)$ & $8(15.4)$ & 3.87 & 0.276 \\
\hline Professional $(n=267)$ & $154(57.7)$ & $64(24.0)$ & $26(9.7)$ & $23(8.6)$ & 31.17 & $<0.001^{*}$ \\
\hline \multicolumn{7}{|l|}{ Income ( $\mathrm{N}=442)$} \\
\hline$\leq 20000(n=81)$ & $28(34.6)$ & $20(24.7)$ & $17(21.0)$ & $16(19.8)$ & 10.03 & $0.02^{*}$ \\
\hline $20001-40000(n=74)$ & $32(43.2)$ & $17(23.0)$ & $12(16.2)$ & $13(17.6)$ & 1.43 & 0.70 \\
\hline $40001-60000(n=80)$ & $36(45.0)$ & $11(13.8)$ & $13(16.3)$ & $20(25.0)$ & 10.4 & $0.01 *$ \\
\hline$>60000(n=207)$ & $117(46.5)$ & $55(26.6)$ & $15(7.2)$ & $20(9.7)$ & 25.85 & $<0.001^{*}$ \\
\hline \multicolumn{7}{|l|}{ Socioeconomic status ( $N=478$ ) } \\
\hline Lower $(n=9)$ & $2(22.2)$ & $2(22.2)$ & $2(22.2)$ & $3(33.3)$ & 4.108 & 0.25 \\
\hline Upper Lower $(n=44)$ & $21(47.7)$ & $9(20.5)$ & $7(15.9)$ & $7(15.9)$ & 0.541 & 0.91 \\
\hline Lower Middle $(n=40)$ & $12(30.0)$ & $8(20.0)$ & $8(20.0)$ & $12(30.0)$ & 12.06 & $0.007^{*}$ \\
\hline Upper Middle $(n=137)$ & $52(38.0)$ & $37(27.0)$ & $23(16.8)$ & $25(18.2)$ & 8.668 & $0.034^{*}$ \\
\hline Upper $(n=248)$ & $144(58.1)$ & $58(23.4)$ & $24(9.7)$ & $22(8.9)$ & 26.52 & $0.001 *$ \\
\hline
\end{tabular}




\begin{tabular}{|c|c|c|c|c|c|c|}
\hline $\begin{array}{c}\text { Are you scared too much of Coronavirus } \\
\text { infection? }(\mathbf{N}=\mathbf{4 7 8 )}\end{array}$ & & & & & & \\
\hline More than half days $(\mathrm{n}=34)$ & $6(17.6)$ & $6(17.6)$ & $10(29.4)$ & $12(35.3)$ & 25.77 & $<0.001^{*}$ \\
\hline Nearly everyday $(\mathrm{n}=77)$ & $17(22.1)$ & $16(20.8)$ & $20(26.0)$ & $24(31.2)$ & 42.11 & $<0.001^{*}$ \\
\hline Several days $(\mathrm{n}=129)$ & $54(41.9)$ & $41(31.8)$ & $17(13.2)$ & $17(13.2)$ & 6.63 & 0.094 \\
\hline Not at all $(\mathrm{n}=238)$ & $154(64.7)$ & $51(21.4)$ & $17(7.1)$ & $16(6.7)$ & 60.83 & $<0.001^{*}$ \\
\hline
\end{tabular}

Table 3.Adjusted association of socio-demographic factors with symptoms of depression

\begin{tabular}{|c|c|c|}
\hline Variables & Odds Ratio (95\% Cl) & P-value \\
\hline Gender & $1.08(0.7-1.69)$ & 0.72 \\
\hline Religion & $1.38(0.81-2.35)$ & 0.24 \\
\hline Age & $0.97(0.95-0.98)$ & $0.001^{*}$ \\
\hline Education & $1.15(0.99-1.35)$ & 0.07 \\
\hline Occupation & $0.96(0.9-1.01)$ & 0.12 \\
\hline Family Monthly Income & - & $0.031^{*}$ \\
\hline Scare from Coronavirus infection & $2.21(1.41-3.45)$ & $0.001^{*}$ \\
\hline
\end{tabular}

${ }^{*}$ p value $<0.05$

In response to question about 'Are you scared too much from Corona?', 238 respondents (49.8\%) reported 'Not at all' while 34 (7.1\%) individuals felt it 'More than half days', $77(16.1 \%)$ individuals felt nearly everyday and 129 (27\%) reported it 'On several days'. When asked subjectively 'Are you feeling depressed?', $72 \%(n=344)$ responded as 'No'.

Female gender, religion, education status, unemployment and professional occupation, income less than Rs. 20000 and more than Rs. 40000, 'scare for coronavirus infection' were found to be significantly associated with severity of depression $(p<0.05)$. Age was not found to be significantly associated with severity of depression (Table 2 ).

As shown in Table 3, adjusted analysis revealed that age was protective factor with respect to severity of depression where as those who were scared from coronavirus infection were found to be two times more at risk of having symptoms of depression. Increasing family income was also associated with presence of depressive symptoms.

\section{Discussion}

The present study revealed the presence of depressive symptoms across more than half of the respondents (51.7\%) during the COVID-19 pandemic. The findings are alarmingly high when compared to $33.7 \%$ reported in systematic review of 14 studies by Salari et.al in July, $2020 .{ }^{8}$ The reason for such contrasting findings could be due to difference in study tools used for diagnosing/ screening of depressive symptoms in these studies. Also, it is well known that resource limited settings impose greater psychological impact on the population due to apprehensions and anxiety among people regarding their own health systems' capability to cope with pandemic situations. Nevertheless, findings in our study point to the need of identifying and examining mental health status of people in these unprecedented times.

Female gender was found to be significantly associated with severity of depression in the present study. This is in line with epidemiological evidence gathered elsewhere. ${ }^{11,12}$ Participants with higher education status were found to have more severe forms of depression. Studies among Iranian and Chinese general population during COVID-19 outbreak showed similar findings. ${ }^{13,14}$ This could be attributed to increased self awareness about their own health among individuals with higher education status. Greater access to information could also be responsible for depression among this group.

Even though ageing did not come as significant factor associated with depression in uni-variate analysis, it emerged as protective factor in adjusted analysis in the study. Aged population are at increased risk of mortality due to COVID-19, yet during pandemic younger age group respondents were found to experience more depressive symptoms in current study. The possible explanation for this paradoxical phenomenon could be over-concern of younger age group about the future consequences of their jobs or businesses resulting due to pandemic. This being an economically productive working force, is getting affected by redundancies and business closures. ${ }^{8,13}$

Scare about Coronavirus infection is surely contributory in exacerbating depressive symptoms. This is consistent with results of our study. Constantly watching or hearing 
COVID-19 related news some of which is fabricated could be distressing to the mind and contribute in creating fears and anxieties among people. Therefore, it is suggested to practice health promoting behaviours and receiving updated and accurate information from authentic sources of information. Optimistic thoughts and positive attitude during COVID-19 pandemic times act as protective factors against depression. ${ }^{15}$

Strengths and limitations of study: There were several strengths of the study. The study tool was validated and sample included for analysis was more than estimated. Despite being an online survey, the response rate of the survey was fairly good. However, our research had few limitations also. The study was periodic and cross-sectional in nature. Periodicity reflects the psychological status of population in certain period of time and may not portray it with evolution of pandemic and consequent changes in surrounding environment. Therefore, there is need to assess the psychological impact of COVID-19 pandemic among people over a longer period of time. Secondly, there was selection bias as only contacts of the research investigators were approached for the survey. ${ }^{16}$ This reflects in higher proportion of participants being of higher education status and engaged in professional occupations. This limits the generalizability of findings of the study.

Limitations not withstanding, the research provides useful insight of the psychological status general population in the country during COVID-19 pandemic. The high proportion of participants reporting depressive symptoms is worrisome. The study findings imply the need for assessing psychosocial impact of COVID-19 among populations and communities in varied settings over a long period of time.

\section{Conflict of Interest: None}

\section{References}

1. Pfefferbaum B, North CS. Mental Health and COVID-19 pandemic. NEJM 2020; Published Online April 13, 2020. DOI: 10.1056/NEJMp2008017.

2. Li J, Yang Z, Qiu H et al. Anxiety and depression among general population in China at the peak of the COVID-19 epidemic. World Psychiatry 2020; 19: 249-250.

3. Qiu J, Shen B, Zhao M, Wang Z, Xie B, Xu Y. A nationwide survey of psychological distress among Chinese people in the COVID-19 epidemic: implications and policy recommendations. Gen Psychiatr 2020; 33: e100213.

4. Yuan S, Liao Z, Huang $\mathrm{H}$ et al. Comparison of the indicators of psychological stress in the population of Hubei province and non-endemic provinces in China during two weeks during the coronavirus disease 2019 (COVID-19) outbreak in February 2020. Med Sci Monit 2020; 26: e923767.

5. González-Sanguino C, Ausín B, Castellanos MA et al.
Mental health consequences during the initial stage of the 2020 coronavirus pandemic (COVID-19) in Spain. Brain Behav Immun 2020; 87: 172-176.

6. Wang C, Pan R, Wan X et al. Immediate psychological responses and associated factors during the initial stage of the 2019 coronavirus disease (COVID-19) epidemic among the general population in China. Int J Environ Res Public Health 2020; 17: 1729.

7. Moreno C, Wykes T, Galderisi S et al. How mental health care should change as a consequence of the COVID-19 pandemic. Lancet Psychiatry 2020; Published Online July 16, 2020. https://doi.org/10.1016/ S22150366(20)30307-2.

8. Salari N, Hosseinian-Far A, Jalali R et al. Prevalence of stress, anxiety, depression among the general population during the COVID-19 pandemic: a systematic review and meta-analysis. Global Health 2020; 16: 57. https://doi.org/10.1186/s12992-020-00589-w.

9. Murthy RS. National Mental Health Survey of India 2015-2016. Indian J Psychiatry 2017; 59(1): 21-26. DOI: 10.4103/psychiatry.IndianJPsychiatry_102_17.

10. Kroenke K, Spitzer RL, Williams JB. The PHQ-9: validity of a brief depression severity measure. J Gen Intern Med 2001; 16(9): 606-613. DOI: 10.1046/j.15251497.2001.016009606.x.

11. Liu D, Ren Y, Yan F, Li Y, Xu X, Yu X et al. Psychological Impact and Predisposing Factors of the Coronavirus Disease 2019 (COVID-19) Pandemic on General Public in China. 2020. Available at: https://ssrn.com/ abstract=3551415.

12. Wang Y, Di Y, Ye J, Wei W. Study on the public psychological states and its related factors during the outbreak of coronavirus disease 2019 (COVID-19) in some regions of China. Psychol Health Med 2020; 30: 1-10.

13. Moghanibashi-Mansourieh A. Assessing the anxiety level of Iranian general population during COVID-19 outbreak. Asian J Psychiatr 2020; 51: 102076.

14. Zhang Y, Ma ZF. Impact of the COVID-19 pandemic on mental health and quality of life among local residents in Liaoning Province, China: a cross-sectional study. Int J Environ Res Public Health 2020; 17(7): 2381.

15. Zhou S-J, Zhang L-G, Wang L-L, Guo Z-C, Wang J-Q, Chen J-C et al. Prevalence and socio-demographic correlates of psychological health problems in Chinese adolescents during the outbreak of COVID-19. Eur Child Adolesc Psychiatry 2020; 29: 1-10.

16. Heena, Nazli T, Grover S, Kishore J. Covid 19 Pandemic and "Feeling Depressed": An Online Survey. Epidem Int 2020; 5(2): 27-31. 